\title{
Research Paper: Communicable Diseases Surveillance System in Iran: Strengths and Weaknesses 30 Years Following its Implementation
}

\author{
Reza HabibiSaravi $^{1^{*}}$ (D, Hamidreza Khankeh² ${ }^{\text {DD }}$, Arash Azar ${ }^{3}$ (D) Fariba Ghasemihamedani $^{4}$ (D) \\ 1. Center for Disaster Management and Medical Emergencies, Mazandaran University of Medical Sciences, Sari, Iran. \\ 2. Research Center in Emergency and Disaster Health, University of Social Welfare and Rehabilitation Sciences, Tehran, Iran. \\ 3. School of Public Health, Faculty of Medicine, University of Sydney, Sydney, Australia. \\ 4. School of Health Management and Information Sciences, Iran University of Medical Sciences, Tehran, Iran.
}

\begin{tabular}{|c|c|}
\hline $\begin{array}{l}\text { Use your device to scan } \\
\text { and read the article online }\end{array}$ & dtation: HabibiSaravi R, Khankeh H, Azar A, Ghasemihamedani F. Communicable Diseases Surveillance System in Iran: \\
\hline 口类得: & $\begin{array}{l}\text { Strengths and Weaknesses } 30 \text { Years Following its Implementation. Health in Emergencies and Disasters Quarterly. 2019; } \\
\text { 5(1):25-36. http://dx.doi.org/10.32598/hdq.5.1.34.1 }\end{array}$ \\
\hline 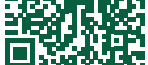 & dolj http://dx.doi.org/10.32598/hdq.5.1.34.1 \\
\hline
\end{tabular}

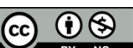

Article info:

Received: 04 Apr 2019

Accepted: 10 Aug 2019

Available Online: 01 Oct 2019

Keywords:

Communicable disease,

Infection, Control,

Surveillance, Iran

\begin{abstract}
Background: Communicable diseases are one of the main health problems in Iran. This study aimed at demonstrating the progress of communicable diseases management in more than 30 years of its implementation and pointing out its strengths and weaknesses, as well.

Materials and Methods: This interview-based study using content analysis method was conducted in 2014. Data were collected through deep interviews. Fifteen interviews were conducted with all experts and health system managers at Iran's communicable diseases management center. The collected data were analyzed using the principles suggested by Strauss and Corbin.

Results: The establishment of the communicable disease surveillance system was a revolution in the health system of Iran. The strengths of the system are as follows: networkbased and integrated health services, well-organized and knowledgeable personnel, national and international supports, strategic and operational plans, and expanded programs of immunization. On the other hand, its weaknesses mentioned by the participants were: disease-based case definition, poor public awareness, poor inter-sectoral collaboration and coordination, insufficient resources, delayed or no notifying target diseases, lack of district laws or incomplete implementation of legislation, failure to provide feedback or ignoring for the results of the analysis, and lack of performance evaluation.

Conclusion: Although the implementation of the communicable diseases surveillance system was a huge achievement in the health system of Iran, however, it needs more improvements based on the present situation. Revision of the rules, restoration and strengthening of the existing structure, the use of modern information and communication technologies, and the establishment of the monitoring and evaluation system are helpful to increase its success.
\end{abstract}

\section{* Corresponding Author:}

Reza HabibiSaravi, PhD.

Address: Center for Disaster Management and Medical Emergencies, Mazandaran University of Medical Sciences, Sari, Iran.

E-mail:drhabibisaravi@hotmail.com; rhabibisaravi@mazums.ac.ir 


\section{Introduction}

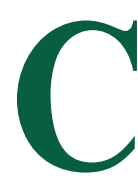

ommunicable diseases have been given a high priority in national health programs indifferent countries because of their high impacts on the public health. It was initiated in Almaty, when the international community changed its approach to "Health" in 1978 [1], continued by improvements in global health strategies, such as "Health for All by the Year 2000" and "International Health regulations 2005 (IHR2005)" [2]. Such measures have resulted in a decrease in the mortality rates in different societies, specifically those caused by infectious diseases, and an increase in life expectancy in the international community.

Iran as one of the countries pioneer in the enhancement of public health in the Eastern Mediterranean region, has tried to demonstrate its commitment to fundamental international treaties of health for all to improve the health level of Iranians. According to Article 29 of the Constitution of the Islamic Republic of Iran, every Iranian has the right to access the highest attainable level of health, which is provided by the Ministry of Health and Medical Education (MOHME) [3]. To achieve this goal, Iran based its health care system on the approach known as "Primary Health Care (PHC)" and expanded the basic health care services to the most remote areas of Iran by establishing a healthcare network [4].

This unique health system of Iran in the Eastern Mediterranean region includes three levels of service provision. Health Houses and Rural Health Centers are considered in the first level (primary care). A Health House provides PHC for a population of 500-2500 people living in a village or a group of villages in rural areas. Health workers of the Health Houses are called "Behvarz" that are trained for two years. A Health Center covers 4-7 Health Houses, in which general physicians and health technicians are working [5].

Health Posts and Urban Health Centers also are in association with Health Houses and Rural Health Centers in urban areas. Health technicians provide health services in Health Posts. The second level of the healthcare system includes district Health Centers and General Hospitals. This level supervises the first level of the healthcare system and also provides more advanced treatment for patients. Health deputies of the medical universities as well as educational and tertiary hospitals benefited from specialist services are the third level of the healthcare system [6].
Providing healthy drinking water, hygienic wastewater management systems, appropriate nutritional programs, public immunization and establishing a healthcare system for communicable diseases are the other measures taken to enhance public health in Iran. In this system, reporting the cases of previously defined target diseases has been introduced as the basis of the National Communicable Diseases Surveillance System (NCDSS) [7].

Surveillance of communicable diseases is a continuous and systematic process of data collection, compilation, collation, and analysis and also the information feedback to those responsible for disease control programs. Communicable diseases surveillance has two components:

1. Information system: Providing information on the occurrence of the disease under surveillance regarding the person, place and time.

2. Epidemic investigation system: Collecting and analysis further information to discover why an Epidemic is occurred and how it can be controlled and prevented.

The communicable diseases surveillance system is essential for the efficient planning of health services. Monitoring the trends of the disease and measuring the impact of control programs are other important goals in this system. In NCDSS, targeted infectious diseases must be reported. The list of notifiable diseases has been introduced by the MOHME based on the guidelines by the World Health Organization (WHO). The list of nationally notifiable infectious diseases is periodically revised regarding the outbreaks of new pathogens or a decline in the incidence of the diseases.

The mandatory reporting of the targeted infectious diseases by clinicians and all other healthcare professionals is enforced by the Iranian law. This approach was adopted to enable the healthcare system to implement appropriate and guaranteed policies to manage communicable diseases effectively [8]. Although this program considering its associated weaknesses and strengths has provided a considerable success for the Iranian healthcare system in last few decades, its efficacy is not promising due to its short history [9].

Accordingly, the Center for Communicable Diseases Management (CCDM), in the MOHME experienced some changes to enhance NCDSS and increase its efficacy while the initial framework of the communicable diseases surveillance system is preserved. In this study, we tried to analyze the weaknesses and strengths of the 
NCDSS leading to revisions and changes in this system through the last few years.

\section{Materials and Methods}

In this study, content analysis method was used for the subjective interpretation of the data obtained from interviews through a systematic classification approach for coding and identifying concepts in 2014. Fifteen precoordinated interviews with experts and heads of departments in the CCDM were conducted in the interviewees' offices at the MOHME in a quiet and comfortable environment. The participants' inclusion criteria were purposefully based on their specialized responsibility in the CCDM. The participants' demographic characteristics are presented in Table 1.

The appropriate sample size was achieved by data saturation and the interviews were continued until the saturation of each concept. Each interview lasted $42 \mathrm{~min}$ (ranged 36-64 $\mathrm{min}$ ). The interviews were conducted in Persian as the formal language of Iranian people. The interviews were deep and semi-structured. An interview guide with a list of basic and general questions was used (Appendix 1).

Depending on the responses to the predefined questions of the interview guide, the additional declaration was asked for better clearance during interviews if needed. The data were analyzed manually based on the principals by Strauss and Corbin [10]. Data collection and data analysis were done simultaneously to identify the tips, which then guided the next interview.

Interviews were reviewed several times and keywords were determined in the text in the open coding phase followed by extracting primary codes. Then, the extracted codes and data were compared for similarities and differences and the categories and sub-categories were determined. Considering the content analysis method [10], all interviews were analyzed by the same analyzer. Data validation was carried out by member check [11]. During this process, the transcriptions and a summary of primary results (codes and categories) were checked by the participants to improve trusteeship. Twenty-three categories were extracted and 8 and 15 categories were classified as strengths and weaknesses.

\section{Description of national communicable diseases Surveillance system}

The Expanded Program on Immunization was launched in 1984 aimed at protecting target groups against mumps, rubella, measles, polio, tetanus, pertussis, diphtheria, viral hepatitis, and tuberculosis. Communicable diseases as a national or international health concerns have targeted by the Routine Communicable Diseases Surveillance System (RCDSS). They are categorized into two groups based on their urgency of notifying. The latest version of the list of diseases that require immediate notification (telephon or fax) are human and bird influenza, botulism, dengue fever, recurrent fever, yellow fever, Crimean-Congo hemorrhagic fever, tularemia (rabbit

Table 1. The subjects' demographic characteristics

\begin{tabular}{|c|c|c|}
\hline Variables & Charactristics & No (\%) \\
\hline \multirow{2}{*}{ Gender (n\%) } & Male & $10(66.67)$ \\
\hline & Female & $5(33.33)$ \\
\hline Job experience (y) & Mean(SD) & $18.9(6.67)$ \\
\hline \multirow{3}{*}{ Level of education ( $\mathrm{n} \%$ ) } & Medical doctor & $7(46.65)$ \\
\hline & General practitioner & $7(46.65)$ \\
\hline & Master of science & $1(6.7)$ \\
\hline \multirow{8}{*}{$\begin{array}{c}\text { The role in the Center for Communicable } \\
\text { Diseases Management No (\%) }\end{array}$} & Surveillance & $4(26.7)$ \\
\hline & Foodborne diseases & $1(6.7)$ \\
\hline & Vaccination & $1(6.7)$ \\
\hline & Viral hepatitis & $1(6.7)$ \\
\hline & Zoonotic diseases & $1(6.7)$ \\
\hline & Tuberculosis and leprosy & $2(13.3)$ \\
\hline & Malaria & $3(20)$ \\
\hline & AIDS & $2(13.3)$ \\
\hline
\end{tabular}


fever), rabies, animal bites, diphtheria, rubella and congenital rubella, measles and febrile skin rashes, pertussis, plague, outbreaks of water and foodborne diseases, acute flaccid paralysis, adult and infant tetanus, malaria, meningitis, and cholera (El Tor).

Diseases subjected to non-immediate reporting (weekly or monthly) are AIDS, Pediculosis and scabies, brucellosis, typhoid fever, leprosy, tuberculosis, anthrax, shigellosis, sexually transmitted infections (syphilis and gonorrhea), Fascioliasis, leptospirosis, cutaneous and visceral leishmaniosis, snakebite, and viral hepatitis (A, B, C, and E).

Communications and reports are two-sided, i.e. data are collected from the first, second and third levels of health services and are concluded and analyzed in the health centers and district level. Then, the reports are sent to the secondary health centers of the provinces and finally to the CCDM at the top of this system at the MOHME. During this process, each layer provides other layers with feedback and this trend continues as it is described in national protocols and all the data are recorded manually or electronically in the predefined forms.

\section{Results}

\section{Interview data}

\section{Strengths}

Network-based and integrated Health services: The existence of a network system for providing PHC with more than 17,000 health houses and above 3000 health and treatment centers has resulted in equal and fair access to health services nationwide.

One of the interviewees said: "Patients have a very good access to this network, especially in small towns and rural areas. They can easily go and receive services, such as treatment, preventive measures, or immunizations. On the other hand, all additional health-related programs e.g. training $\mathrm{s}$ for health and treatment staff or implying national or international health programs can be easily merged into this system in order to be operated easily across the country. In this system, none of the units in a certain level, would provide services, which are assigned to lower level units, unless these services are provided at a higher level".

Well organized and knowledgeable personnel: An effective arrangement of health care providers at different levels without spending huge funds for training them and varied health services provided by different sectors of the system has resulted in high-quality services and low cost. People at their different defined positions have received adequate training relevant to their provided services and can competently deploy new mandated health regulations without having advance qualifications.

One of the specialists mentioned: "This health care system is very simple and practical, while being based on science. Fortunately many people who play a role in this health care system are not necessarily highly qualified. They have the minimum academic education or even might be uneducated. But they are fully trained in short courses and are fully aware of their responsibilities in order to pursue the goals of the health care system".

A health unit manager said: "Although being very simple, the health care system of the country is yielding precious results. In other words the health care system of the country is a symbol of a cost-effective investment in which a small investment is followed by high achievements in the health care system of the country".

National and international supports: The commitment to the fulfillment of large-scale national projects in the health care system, achieved by high-ranked governmental authorities and the support provided by governmental organizations and institutions, such as the Islamic Consultation Assembly (i.e. The Parliament) or the supreme leadership has been very productive.

One of the managers said: "Such huge projects can never be accomplished without the political support of the parliament, the government the president and the supreme leader. The system has made strategies, allocated funds, planned, passed laws, provided the necessary platforms and has trained the required workforce so that the healthcare system has reached where it is now. On the other hand, WHO as one of the most influential organizations which collaborate closely with the U.N has a global approach in its projects. It plays a key role in designing plans in their simplest forms, based on objective evidence and facts, suitable for poorest countries with the lowest level of facilities".

One of the health professionals said: "WHO is the best example of globalization. The concept of having a global village, one society and one country on earth, could be achieved through such an organization. Its projects are evidence-based and practical. The existence of WHO is an opportunity for us. We wouldn't be successful in achieving our goals without it because this organization proposes commitments and provides international sup- 
port for developing countries to keep (the prevalence of their endemic) diseases under control".

"WHO is technically a provider of scientific reference for diseases. When WHO announces directives about diseases, they are highly accurate and everybody accepts them as they are based on the consensus of professionals to achieve the best possible result in controlling communicable diseases".

Strategic and operational plan The special geographical position of Iran in the center of the Middle East, bordering countries that some of them are a center for internationally important communicable diseases, mandates being equipped with necessary strategic and operational plans.

In this regard, the Ministry of Health, Treatment, and Medical Education relying on the scientific expertise of its professionals and technical guides by the WHO, designs and initiates necessary plans based on the special needs of the country. It has already designed several beneficial plans using this approach, which has been adopted by the WHO as a pattern to be used in other countries in several occasions.

One of the specialists said: "Concerning the geographical position of our country and our neighboring countries, we readily need special plans to control communicable diseases which are imported through the borders. We cannot ignore our geography of this region. When outbreaks happen in our neighboring countries, we get involved each time. These plans can vary from (short-term) operational plans to long-term plans of several years. It is particularly very necessary to have a plan to achieve the goals which are set by the healthcare system".

The Expanded Program of Immunization (EPI): Undoubtedly, vaccination has had a pivotal effect on the public health. Following access to healthy drinking water, vaccination has had the most important role to decrease mortality rates, especially among children and an increase in population growth rates. Although national immunization program of Iran dates back to 1829 against smallpox, in recent 30 years, after the launch of the Expanded Program on Immunization (EPI), considerable progress was achieved to prevent and control preventable diseases.

After the launch of EPI, congenital measles and rubella have eradicated and polio has not been reported for more than 14 years ago. Newborn tetanus has eradi- cated and diphtheria, pertussis, and mumps have been controlled. The prevalence of chronic hepatitis B careers has declined from $3 \%$ in 1991 to less than $2 \%$.

The most effective strategy to obtain such achievements in RCDSS is the high coverage population (children and other target groups), which is $95 \%$ at the level of districts or nationwide.

One of the managers said: "The high quality of children immunization plan together with its high coverage, have resulted in control, elimination or eradication of target diseases nationwide which is an important achievement in providing public health".

\section{Weaknesses}

Disease based Case definition: The target groups in the current RCDSS were defined based on the diseases. Patients are categorized into three groups of suspicious, probable, and certain in the diagnosis process of the new cases. Reporting new cases will happen after diagnosis of the disease and when patients have passed these three transitional stages. This lengthy process will result in a delay in reporting.

One of the specialists pointed that: "The disease-based surveillance system, lead us to the result too late since we had to wait for the disease to appear before we can report it". In this approach, the output of the surveillance system would not be practically useful in making swift strategic decisions.

One of the managers stated: "I would say that surveillance system, in its routine shape, didn't have many points of strength. Its basic problem was the fact that it was not designed for the idea of "information for action" in the first place. They improved it gradually though. Endemic diseases of this region and geographical pathology were included later. They finally realised that this surveillance system is not effective for our current situation".

Insufficient public awareness: Public health education is crucial for successful health plans, specifically those related to the surveillance of communicable diseases. Awareness of people about healthy drinking water, nutrition and wastewater management is one of the major aspects of plans designed to control communicable diseases. Public health education will be very effective, if it is delivered in a continuous and goal-oriented manner.

The RCDSS works passively, i.e. it is designed based on the doctors' reports. Basically, if patients do not refer to 
the doctors on time or at all, the healthcare system cannot control the spread of the communicable disease timely.

One of the managers pointed out: "There are people with low level of knowledge who have nutrition problems, do not drink healthy water and do not perform disposal of their garbage and wastewater appropriately. A certain percentage of them, even do not go to doctors or the health care system when they are sick and prefer to treat themselves. Such people cause a huge issue for the healthcare system".

The manager of one of the departments said: "We should consider the fact that people of our society do not have enough knowledge about different diseases. Some of them admit to this fact that they do not know much about diseases but there are others who have some limited knowledge mixed with some wrong information. Each group have their specific issues. If people do not know the hazards of being in contact with communicable diseases, they will not be sensitive.

Therefore, health education and public awareness are of paramount importance for people to help them decide whether they should or should not report it if they see a patient with measles or polio and what the significance of that will be. People will not cooperate with us in this system if we don't inform them about its importance. It is assumed that people should demand services from the healthcare system. Since they are not asking for services it is our responsibility to inform them about our services. That's why I think our biggest challenge is providing information for people by our doctors and health specialists. They should notify people since it is one of the effective measures".

Poor inter-sectorial collaboration and coordination: Cooperation between different institutions and entities of the health system, even the private sector is necessary to achieve the RCDSS goals. Positive changes have taken place during recent years, however, relevant bodies, specifically the private sector suffer from inadequate intersectoral coordination. Even on some occasions, some parallel works and hustles have happened unintentionally.

One of the managers said: "Our health care system consists of public and private sectors. The private sector hasn't been successful in delivering services while the public sector is among the best healthcare systems in the world. If we could involve the private sector as well, our healthcare system would be exceptional. The low level of participation of the private sector can be attributed to lack of motivating factors and feedbacks".
Another manager also pointed out that lacking plans and regulations is not a reason for our problems; not being committed to the plans is the main cause: "I want to put it that way, you don't have theoretical difficulties in surveillance, and all problems are administrative. Maybe, we need to pass legally binding laws. A fundamental work requires a pervasive approach. It means, it necessitates intersectoral collaborations. Unfortunately there is a feeble cooperation between the ministry of health and other sectors such as municipalities, industrial units and Water and Wastewater Management Department. A foundational plan for prevention necessitates a comprehensive contemplation".

The Islamic Republic of Iran Broadcasting (IRIB), as the national Iranian television, and other governmental media in can be effective, however, they do not cooperate with the health care system appropriately. One of the managers stated: "Large-scale strategies of the country need to be supported. If they want to support the healthcare system, they need to publicize it. But when we want to announce a message publically, IRIB asks for money. They believe our announcements are commercial advertisements. IRIB should change its approach and should not charge us for our vital plans related to public health, a plan which pursues one of our strategically goals for the third millennium of development. Other media such as newspapers also should not charge us for our notices or announcements for vaccinations. This issue needs to be resolved by the support of policymakers".

Insufficient resources: Appropriate conduction of plans requires access to prepared and substitute resources. In the initial stages of the Service Network System, followed by the Healthcare System, the funds, equipment, and workforce were allocated appropriately, which yielded a huge success through those years. Gradually, the population increased and the services were expanded, however, resources were not renewed or increased.

One of the managers mentioned: "There are several gaps which we need to fill. Health workers (Behvarz) are ageing and becoming less productive and can't work as well as they used to. We need to replace them with a new group. Health Houses are worn out and finally, we need new and more advanced equipment. In recent years, the quality of services in the network system has diminished for different reasons. For example, (Directly Observed Treatment Short-course) (DOTS) is not carried-out ideally and we are far from its minimally accepted quality because we haven't defined a position for a TB coordinator doctor although we have defined positions for family doctors. 
Another manager pointed out: "In fact, this is a discussion about funds. We need funds for any executive activities, without enough funds, we can't carry out our plans. The list of the responsibilities of the ministry of health has increased but enough funds have not been allocated."

Delayed or not notifying target diseases: On-time reporting of the target communicable disease, inconsistency with the defined cases, is one of the bases of the RCDSS. If a delay happens in reporting of the cases, relevant actions would not be taken.

One of the professionals stated: "delayed reporting is an issue. Reports are mainly paper-based, when sending and receiving of reports should be done by the human, errors will increase if reporting is based on humans. We can decrease human errors by using machines. Reporting of some diseases have already been changed into electronic form but they still seem to have a lot of issues. Since human should enter the data to computers we can still have human error and since it is a time-consuming process it may cause some delays in reporting.

On the other hand lack of cooperation from some of the facilities in private and even public sector can cause disturbances and can decrease its functionality. A proportion of the problem is due to misunderstandings of the health care providers about surveillance systems. Some diseases are very rare and health care providers are not aware that they are reportable. One of the professionals said our colleagues in public or private medical centers might not know all the 150 communicable diseases which are our target diseases. Some of these diseases are not endemic in Iran but can be imported so they may encounter with them."

None-compliance with the system can occur in large cities twice as much. One of the managers said: "The main problem occurs in large cities where we don't have many of the data. The private sector covers a large proportion of cases in the large cities, there, many cases are not recorded or referred or they might be referred to other parts of the private sector where there is no recording and reporting system. This issue doesn't let us have accurate information about the situation of diseases in large cities. It means we have a faulty data gathering, so, when it is time to intervention, we cannot make the right decision. All the decisions would be wrong because they are based on wrong data. That's when the whole surveillance system will be questioned".

Not enforcing the law or incomplete implementation of legislation: Although based on the rules all the health care providers are required to report cases of communicable diseases in both public and private sectors, due to non-compliance with the rules in public and private sectors, communicated diseases are not correctly and timely reported. They are even sometimes never reported.

One of the managers mentioned: "as it is defined, all the hearth care providing centers should cooperate with us in gathering data but this has not happened practically. Nowadays all our focus is on public sector because private and charity sectors do not cooperate". On the other hand, the laws regarding reportable diseases were enacted in 1949 based on the situations of that era. Therefore, it can hardly be considered as a legally binding law.

One of the professionals said: "there is a law but we believe we are science oriented. All the health care providers are educated people. In all medical books, It is written that doctors need to report it if they find a case of communicable diseases. Even if there was no legally binding law, as a doctor, you are responsible for the public health. You have sworn to report communicable diseases and it is an infringement if you don't report them. From the legal point of view, we know that there is a law. Although this act has not been updated. I personally believe, we cannot handle this issue only by passing laws.

We need to propose some incentives for the private sector. Accusation and denunciation of the private sector do not help. Whether we like it or not, a large proportion of the healthcare is done by the private sector. We won't be successful if we can't obtain their cooperation. We are not competing with the private sector. We should employ the private sector as a sector which plays a crucial role in public health. We can't ensure their cooperation to improve public health without such incentives and only by relying on our laws which are not strong enough, in my opinion".

Failure to provide feedback or disregard for the results of the analysis: Presenting the obtained results to those involved in different parts of the healthcare system is one of the most important tasks of the surveillance system. This trend helps high-ranking decision-makers to make determinant decisions and increases the enthusiasm for further collaborations within the counterpart organizations, which leads to better accomplishment of the goals of the surveillance system. This feedback is also crucial for those providing report and even health workers in the primary level of the health care system.

One of the professionals explained this subject in detail: "There might be different flaws, more or less, in different parts of the surveillance system such as data 
gathering, data registration, data reporting, data analysis or publication of the results. In my opinion, our weakest link is the last one. Even if we believe that we have established a flawless system, what are we going to do with our analyzed data? Who is going to use them? Should we archive them and say we are done? The product of the surveillance system is not for use in one single organization. These data should be utilized in highest levels of decision-making by policymakers in different governmental organizations.

As a result of frequent changes in their positions, many of the authorities even don't know surveillance system and have no idea about its applications and significance. Our most important defect is in our process of publication and distribution of our results and preparation of feedbacks for collaborating bodies and decision-making authorities. Currently, there is no established framework for publicizing the results. Different parts of the ministry of health may publish the results based on their own choice and taste. At a lower level, the ministry of health in different provinces might or might not have periodicals or journals for the surveillance system. Our inefficient publication, seems to be one of our most important defects".

Lack of performance evaluation: Performance evaluation is one of the most important bases of systematic management to appraise the plan to enhance its efficiency by resolving possible problems. The RCDSS has lacked a comprehensive scientific evaluation system. One of the managers mentioned: "The question is, In fact, how is our performance? For example, have we allocated enough workforce for our different projects in the CCDM based on the expansion of the affected population, geographical situations, endemic diseases and possible outbreaks? Although, in different sections of the system, might have developed different types of evaluation processes under different conditions, the critical issue is the absence of an external evaluation system conducted by investigators with no affiliation to the executive workforce of the surveillance system".

Another professional said: "We do have a system named, the surveillance system but how is it evaluated? We audit it and find some defects here and there but we never evaluate it officially to see if this system works properly or not. A scientific evaluation has its processes and rules and we need to evaluate the system based on them to find the defects and resolve them. Suppose you take a spelling test but there is no one to check your spelling! They ask you to check your own spelling; even if you do it, there should be someone to grade it for you. This issue is a considerable flaw in the system".

\section{Discussion}

The purpose of the present study was to investigate the conditions of the surveillance system for communicable diseases, express its strengths and weaknesses through its establishment (30 years), and indicate the factors leading to changes in its performance in recent years.

One of the most important strengths of the CDMS in Iran is the existence of network-based health services with trained and qualified staff and, consequently, a systematic reporting of the cases of communicable diseases. In addition, the expanded coverage of vaccination in target groups, using the very simple, appropriate, and efficient protocols, as well as guidelines by the WHO empowered the effectiveness and efficiency of the NCDSS. Several similar systems have achieved successful results worldwide, especially in developing countries [12, 13].

Perhaps one of the reasons for the success of the NCDSS in Iran is the commitment of its elements, especially by government and managers. This is the key element of the success for all sustainable services worldwide, particularly CDSS [14]. Although the law has been enacted in the parliament to control communicable diseases, its binding nature has declined because the penalties are not adequately strict. Based on the participants' opinion, the penalties were appropriate at the time of the enactment of the law and they are currently not sufficient to engage the partners to cooperate and are needed to be reviewed and updated. In addition, incentives for those with good cooperation in case reporting can be a complement to the law.

One of the weaknesses reported by the participants was the definition of the disease and the process of case reporting which led to a delay in the report and, as a result, loss of time to implement the necessary measures to control the epidemic. This issue has been a problem in other countries, including developed countries [15]. To solve this issue, in recent years, in collaboration with the WHO, the definition of a syndromic surveillance system has been developed as a complement to the NCDSS leading to a faster report of cases and also the implementation of outbreak control programs. This system has shown effective even in disasters in Iran [16].

On the other hand, in recent years, with the implementation of the family physician program in two provinces of Iran, Mazandaran, and Fars, benefitted from electronic systems and recording all health-related data at referral to patients, a new horizons has opened in timely reporting communicable diseases in the health system of 
Iran. Another weakness of the system was the inadequate awareness of people regarding contagious diseases and how to deal appropriately with them, which directly and indirectly affects CDSS.

According to the experts' views, despite all the efforts made in Iran from schools to universities, as well as public education through the media, the public awareness is at the low level. However, awareness is varied through the country depending on the economic, social, and cultural conditions of the regions. For example, inhabitants of the southeastern regions of Iran did not participate in the malaria control programs, and despite enough training and providing the necessary information, they have not been cooperated to control the disease [17]. Considering the nature of the communicable diseases, public awareness, as one of the important pillars of self-care, not only reduces the mortality and morbidity of the disease but also strengthens people's collaboration with the CDSS [18].

The lack of coordination and cooperation among all actors in the health system in controlling communicable diseases, especially the private sector, is one of the most important weaknesses of the CDSS in Iran. This issue is of great importance not only in Iran but also in other developing countries, as one of the most important problems to control communicable diseases [19], which is more serious in emergencies, as noted in the performance evaluation of the health sector response to the Katrina hurricane in the United States [20, 21]. However, several successful examples, such as Europe can be mentioned. In Europe, coordination and cooperation, even across the continent, led to control pandemic H1N1 influenza successfully [22].

Another weakness of the CDSS was no timely reporting or even no report of target cases by the first-line health workers that are in contact with patients. This issue not only arises from the private sector but also some governmental agencies do not report target cases. The lack of reporting is the main problem in Iran and has reported as the main problems affecting the surveillance system worldwide, which is specifically addressed in a report by the WHO [23]. However, in addition to the lack of cooperation, in some cases, the lack of knowledge of the notifiable diseases list or unfamiliarity with rare diseases entered from other countries was the main issue that was also reported in study by Konowitz et al. [24]. Such issues highlight the importance of continuous and comprehensive education for health care providers.

Providing different reports to all partners in the CDSS is essential for better control of the outbreaks. These reports are needed at a higher level for more accurate decision making and for the first-line health providers to strengthen their future cooperation. The information provided as feedback from the CDSS can be used for immediate health care planning and assessment, as well as the hypothesis formulation for next investigations [25]. On the other hand, these results can be included in the interventions to effectively prevent new emergence cases, limit the epidemic, improve water quality, affect vector status, and shorten the length of infection, etc. [26]. In addition, one of the reasons for the inappropriate cooperation of the various sectors involved in case notification in CDSS, especially the private sector, was the lack of feedback from CDSS to these sectors, which can lead to disappointment over time.

The purpose of the performance evaluation of the CDSS is to ensure the appropriate continuous monitoring of its target diseases, correct preventive measures, adequate responses, and solving program's shortcomings for future programs [27]. Although the WHO has played a leading role by providing health system assessment protocol and guidelines [28] and the developed countries have been recently trying to improve their health systems by adopting those conceptual and operational frameworks [29], however, no proper systematic internal and external performance evaluation is available in the NCDSS. Nonetheless, considering the importance of this issue, in recent years, the authorities of the CCDM have developed some evaluation systems to improve its performance, of which the CDSS performance evaluation tool in disasters can be mentioned [30].

\section{Conclusion}

The established communicable diseases surveillance system has performed well to control communicable diseases in the early years of its implementation, however, the results have not been satisfactory in subsequent years. The main reasons are as follows: legal penalties are negligible and are not binding, co-workers in the CDSS, especially in the private sector, do not have the incentive to take care of the proper implementation of CDSS, public and professional education is not enough and there is no internal and external performance evaluation.

Enactment of the new law or updating previous legal forces, continuous education of the public to increase awareness, acceptability of the surveillance system in the community, training and frequent training programs for professionals, continuous internal performance assessment, and external evaluation by third parties are suggested to improve the performance of CDSS. Due to the 
vicinity of Iran to various focal points of communicable diseases, such as Afghanistan, Iraq, and Pakistan, evolution, development, and improvement of the NCDSS are necessary.

\section{Ethical Considerations}

\section{Compliance with ethical guidelines}

This study was approved by the Ethics Committee of Iran University of Medical Sciences, Tehran, Iran (Approval No.: 93/D/105/486)

Funding

This study was supported by the Iran University of Medical Sciences, Tehran, Iran (Grant No.: IUMS/ SHMIS_1392/351).

\section{Authors' contributions}

All authors contributed in preparing this paper.

\section{Conflict of interest}

The authors declared no conflict of interests.

\section{References}

[1] Venediktov D. Alma-Ata and after. World Health Forum. 1998; 19(1):79-86. [PMID]

[2] World Health Organization, Regional Office for the Eastern Mediterranean. Primary health care: 25 years after Alma-Ata [Internet]. 2003 [Updated 2003 October]. Available from: https://apps.who.int/iris/handle/10665/122206

[3] Mehrdad R. Health system in Iran. Japan Medical Association Journal. 2009; 52(1):69-73.

[4] Shadpour K. Primary health care networks in the Islamic Republic of Iran. Eastern Mediterranean Health Journal. 2000; 6(4):822-5. [PMID]

[5] 5. Asaei S. Iran's excellent primary health care system. United Nation International Children Emergency Fund (UNICEF) (Online)(Cited 2011 March 20) Available from URL: www unicef org/iran. 2014.

[6] Mosadeghrad AM. Factors influencing healthcare service quality. International Journal of Health Policy and Management. 2014;3(2):77-89. [DOI:10.15171/ijhpm.2014.65] [PMID] [PMCID]

[7] Bagheri Lankarani K, Alavian SM, Peymani P. Health in the Islamic Republic of Iran, challenges and progresses. Medical Journal of the Islamic Republic of Iran. 2013; 27(1):42-9. [PMID] [PMCID]
[8] Asadi-Lari M, Sayyari AA, Akbari ME, Gray D. Public health improvement in Iran-lessons from the last 20 years. Public Health. 2004; 118(6):395-402. [DOI:10.1016/j. puhe.2004.05.011] [PMID]

[9] Nader F, Askarian M. How do Iranian physicians report notifiable diseases? The first report from Iran. American Journal of Infection Control. 2009; 37(6):500-4. [DOI:10.1016/j. ajic.2008.09.014] [PMID]

[10] Corbin J, Strauss A, Strauss AL. Basics of qualitative research: Techniques and procedures for developing grounded theory. Thousand Oaks: SAGE Publications; 2014

[11] Elo S, Kyngäs H. The qualitative content analysis process. Journal of Advanced Nursing. 2008; 62(1):107-15 [DOI:10.1111/j.1365-2648.2007.04569.x] [PMID]

[12] Wetterhall SF, Pappaioanou M, Thacker SB, Eaker E, Churchill RE. The role of public health surveillance: Information for effective action in public health. Morbidity and Mortality Weekly Report. 1992; 41 Suppl:207-18. [PMID]

[13] Nishtar S, Bhutta ZA, Jafar TH, Ghaffar A, Akhtar T, Bengali $\mathrm{K}$, et al. Health reform in Pakistan: A call to action. The Lancet. 2013; 381(9885):2291-7. [DOI:10.1016/S01406736(13)60813-2]

[14] Bino S, Cavaljuga S, Kunchev A, Lausevic D, Kaic B, Pistol A, et al. Southeastern European Health Network (SEEHN) communicable diseases surveillance: A decade of bridging trust and collaboration. Emerging Health Threats Journal 2013; 6(1):19950. [DOI:10.3402/ehtj.v6i0.19950] [PMID] [PMCID]

[15] Miller M, Deeble M, Roche P, Spencer J. Evaluation of Australia's national notifiable disease surveillance system. Communicable Diseases Intelligence Quarterly Report. 2004; 28(3):311-23. [PMID]

[16] Ardalan A, Babaie J, Moradian MJ, Shariati M, Yousefi $\mathrm{H}$. Incorporating the lessons learned from the 2012 East Azerbaijan earthquakes in Iran's national health emergency plan. Prehospital and Disaster Medicine. 2013; 28(4):417. [DOI:10.1017/S1049023X13000319] [PMID]

[17] Rakhshani F, Ansari Moghadam AR, Alemi R, Moradi A Knowledge, perceptions and prevention of malaria among women in Sistan va Baluchestan, Islamic Republic of Iran. Eastern Mediterranean Health Journal. 2003; 9(3):248-56 [PMID]

[18] Celentano DD, Nelson KE, Lyles CM, Beyrer C, Eiumtrakul S, Go VF, et al. Decreasing incidence of HIV and sexually transmitted diseases in young Thai men: Evidence for success of the HIV/ AIDS control and prevention program. Aids. 1998; 12(5):F29-36. [DOI:10.1097/00002030-199805000-00004] [PMID]

[19] Altaras R, Nuwa A, Bosco A, Streat E, Tibenderana J, Strachan C. Track 1: Infectious diseases. Tropical Medicine and International Health. 2013; 18(1):52-107.

[20] Centers for Disease Control and Prevention. Surveillance for illness and injury after hurricane Katrina -- New Orleans, Louisiana, September 8-25, 2005. Morbidity and Mortality Weekly Report. 2005; 54(40):1018-21.

[21] Lyons S, Zidouh A, Ali Bejaoui M, Ben Abdallah M, Amine S, Garbouj M, et al. Implications of the international health regulations (2005) for communicable disease surveillance sys- 
tems: Tunisia's experience. Public Health. 2007; 121(9):690-5. [DOI:10.1016/j.puhe.2007.02.013] [PMID]

[22] Hashim A, Jean-Gilles L, Hegermann-Lindencrone M, Shaw I, Brown C, Nguyen-Van-Tam J. Did pandemic preparedness aid the response to pandemic (H1N1) 2009? A qualitative analysis in seven countries within the WHO European Region. Journal of Infection and Public Health. 2012; 5(4):28696. [DOI:10.1016/j.jiph.2012.04.001] [PMID]

[23] World Health Organization. WHO report on global surveillance of epidemic-prone infectious diseases [Internet]. 2000 [Updated 2000 January]. Available from: https://www. who.int/csr/resources/publications/surveillance/WHO_ CDS_CSR_ISR_2000_1/en/

[24] Konowitz PM, Petrossian GA, Rose DN. The underreporting of disease and physicians' knowledge of reporting requirements. Public Health Reports. 1983; 99(1):31-5. [PMID]

[25] German RR, Westmoreland D, Armstrong G, Lee LM, Birkhead GS, Milstein RL, et al. Updated guidelines for evaluating public health surveillance systems: Recommendations from the guidelines working group. Morbidity and Mortality Weekly Report. 2001; 50(RR-13):1-35. [PMID]

[26] Nare L, Love D, Hoko Z. Involvement of stakeholders in the water quality monitoring and surveillance system: The case of Mzingwane Catchment, Zimbabwe. Physics and Chemistry of the Earth, Parts A/B/C. 2006; 31(15):707-12. [DOI:10.1016/j.pce.2006.08.037]

[27] Nsubuga P, White ME, Thacker SB, Anderson MA, Blount SB, Broome CV, et al. Public health surveillance: A tool for targeting and monitoring interventions. In: Jamison DT, Breman JG, Measham AR, Alleyne G, Claeson M, Evans DB, et al, editors. Disease Control Priorities in Developing Countries. Washington, DC: World Bank Publications; 2006. [DOI:10.1596/978-0-8213-6179-5/Chpt-53]

[28] Murray CJL, Frenk J. A WHO framework for health system performance assessment: Evidence and Information for Policy, World Health Organization [Internet]. 1999 [Updated 1999]. Available from: https://apps.who.int/iris/handle/10665/66267

[29] Hurst J, Jee-Hughes M. Performance measurement and performance management in OECD health systems [Internet]. 2001 [Updated 2001 January 30]. Available from: https:// www.oecd-ilibrary.org/social-issues-migrationhealth/ performance-measurement-and-performancemanagement-in-oecd-health-systems_788224073713 [DOI:10.1787/788224073713]

[30] Babaie J, Ardalan A, Vatandoost H, Goya MM, Akbarisari A. Developing a performance assessment framework and indicators for communicable disease management in natural disasters. Prehospital and Disaster Medicine. 2016; 31(1):2735. [DOI:10.1017/S1049023X15005452] [PMID] 
Appendix 1. Interview guide

Basic and general Questions:

How was the process of establishing the routine communicable diseases surveillance system?

How is the operational trend of routine surveillance system in collecting, interpreting and disseminating data?

What is your idea about the strengths of the routine surveillance system?

What is your idea about the weaknesses of the routine surveillance system?

Depending on responses to initial questions, additional clarifying questions will be asked for better clearance during interviews whenever needed. 